\title{
NOTES ON THE EARLY STAGES OF TWO SPHINGIDAE.
}

\author{
BY ALPHEUS SPRING PACKARD, PROVIDENCE, R. I.
}

It is evident that what little we know, notwithstanding all the effort which has been made, of the life-histories of our sphingidae, will have to be done over again in a more thorough and systematic way, while each stage should be very fully and comparatively described, in order to ascertain the probable relative age both of the species of the genus, and of the genera themselves. In this way we shall be able to arrive at a probable phylogeny of the sphingid family; i. e., we may discover the ancestral forms, i.e., those which have through adaptation survived many ages, and the later, more highly modified species, which are the result of adaptation to newer, changed conditions. One may feel sure that in this attractive labor, he will derive great intellectual benefit and stimulus. It will not only cultivate his powers of observation, but add to habits of reflection, and draw out whatever latent philosophical capacities or tastes may have laid dormant in his nature. In such work Weismann's beautiful "Studies in the Theory of Descent" will be the student's guide, and it is greatly to be desired that our younger lepidopterists should obtain that work and make a careful study of it. From our limited experience in rearing only two or three sphingids, and a number of bombyces, we feel confident that the facts and theories in that stimulating work are as a rule well founded; and we are glad to acknowledge our great indebtedness to the learned and thoughtful author. As the work is well translated by Prof. Meldola, and can be had at a very moderate price, far less than the original cost, there is little excuse for not buying it.

Thus far we have perhaps not a single thorough and well illustrated lifehistory of any of this group, and we are still in much the same condition that they were in Europe, before the publication of Weismann's work. This is not written to depreciate in any way the excellent and honest work which has been done by Messrs. Lintner, Riley, Hulst and others. What we mean to say is that the life-histories thus far published, have not been worked out with reference to the origin of the markings, the lines, stripes and spots; nor with reference to the probable relative ages of the species, nor to the position in nature of the different genera, so as to enable us to determine which are the older or simpler forms, and which the more recent, more modified genera, or species. The work can hardly be done by one person, or in even several seasons, but should a few coöperate, a great deal of desirable work could be in the course of a few years performed.

The few notes below were made during the past summer on two forms allied to those interesting genera Deilephila 
and Thyreus, as well as Philampelus and Chaerocampa. I had no intention of doing any work in this family, and the notes are not intended to be at all final, but imperfect as they are, they show how interesting it would be to know something of the early larval stages of the American species of Amphion, Thyreus, Enyo, Deilephila, Philampelus, and certain tropical forms, to which the genera in question are allied.

\section{Life-history of Deidamia inscrip- tum. (Harris.)}

Mr. James Angus, of West Farm, N. Y. had the goodness to send me the eggs of this sphingid, which is allied to Thyreus abbotii, and I was able to carry it through its stages, while in Brunswick, Maine. As the climate is much cooler there than in New York, the nights especially being much lower in temperature, the length of the different stages will probably be found to be much greater than in New York, The larva, according to $\mathrm{Mr}$. H. Edwards's very useful Bibliographical catalogue of the described transformations of North American lepidoptera, has heen briefly described by Strecker ( Rhopal. et Heteroc. ; I I 2 ) and by Fernald (Sphingidae New England, 7o,) but the early stages have not yet been described. The description of the larva in Strecker's work was however given him by $\mathrm{Mr}$. John Akhurst, from memory, and Prof. Fernald's description is simply copied from Strecker. According to Akhurst the larva is "full-grown about the last of June or beginning of July, and is single- brooded, the perfect insect appearing about the middle of May. Several moths issued in Providence the end of May and early in June from pupae kindly given me by $\mathrm{Mr}$. Angus, but though several males and females were placed within the mating bag no fertilized eggs were obtained. The eggs from which my larvae were bred were received from Mr. Angus, 24 June I 890 .

$E g g .-$ Rounded oval, rounded alike at each end, somewhat longer than broad, length $2 \mathrm{~mm}$.; greenish in color. The shell is thin, smooth when examined under a Tolles triplet of high power, and also under a $\frac{1}{2}$ inch Tolles objective, but with the latter, scattered roughnesses are perceivable, though not forming true granulations.

Stage 1.-Just hatched on the morning of 27 June. Length $3 \frac{1}{2}$ to $4 \mathrm{~mm}$. Head rather larger, wider than the body, which tapers somewhat from the prothoracic segment to the end. It is uniformly smooth, pale yellowish green, the head being exactly the same color as the body. There are on the body no spots or markings of any kind. The body is provided with long slender sparse, granlular, slightly bulbous hairs, about one-third as long as the diameter of the body, which arise from small minute conical warts. The hairs on the head taper to a fine point.

The very slender, filamental " caudal horn" is, if anything, slightly longer than the body ; it is held erect, perpendicularly to the body, and is shining black and very hairy, the hairs being 
short and fine, those in the middle of the horn not being one half as long as the diameter of the appendage. The horn is very slightly divided at the end into two tubercles, each hearing a bristle.

3o June, having fed for two or three days they are now larger than before, being 6 to $7 \mathrm{~mm}$. in length, and now the head is no wider than the body, the latter having after two or three days' consumption of food filled out, so that the body does not taper so much toward the end. There are as yet no spots or stripes on the body. The piliferous warts are present, the four dorsal ones being arranged in a trapezoid; they are faintly marked, and green in color.

At the end of stage I, about 3-4 July the body had grown so that the caudal horn was scarcely two-thirds as long as the body, when 6 to $7 \mathrm{~mm}$. in length. There are now, just before ecdysis, faint traces of a diffuse yellowish line, which is seell more distinctly in stage II, and the granulations on the skin are more distinct than when the larva was first hatched.

Stage II.-4-5 July. Length ro $\mathrm{mm}$. The head is now about as wide as the body, not quite so wide as where the body is thickest, i.e.-at the first abdominal segment. The caudal horn is now only half as long as the body, and is black and hirsute. It is distinctly divided at the end, each lobe bearing a seta as long as the horn at the end is thick. About eight rows of granulations cross each segment, and there is now a faint greenish-yellow lateral line ; but no traces of the oblique lateral stripes can be seen until at the end of the stage. The hairs now have lost their bulbous shape, and taper somewhat to the end. It usually rests on the midrib of the under side of the leaf in this and the preceding stage.

Stage III.-9-I I July. Length $20 \mathrm{~mm}$. 'The head is now proportionately small, narrower than the rather thick body, which is a little swollen on the $3^{\text {rd thoracic and Ist abdominal }}$ segments. The caudal horn is only as long as the body is thick; it is black, becoming pale at the tip, and green on each side at the base. 'There are eight wrinkles across the back of the basal abdominal segments.

There is a very narrow dorsal dark green thread-like line, and a much wider diffuse subdorsal line, the two meeting at the base of the caudal horn; below is a whitish green lateral line also ending on the base of the caudal horn. The oblique lines are yellowish, and much more distinct than at the close of the preceding stage; the bars only extend from the hinder end downward to the front edge of the same segment, not extending upon the next segment. The spiracles are green, not ringed, but bearing two obliquely vertical parallel twin oblong fine black dots. The wrinkles are well marked on the dorsal surface; lower down the sides they break up into raised white spots or granulations. The suranal plate is faintly edged with yellowish.

Stage IV.-Moulted i 4 July. Length 25 to $30 \mathrm{~mm}$. The head is pea-green, 
with a yellowish stripe on each side, continuous with the subdorsal stripe along the body, which is now broad and diffuse, with a dark green shade above it. The lateral yellowish stripes as before. The horn is a little shorter than in the preceding stage, and the green at the base on each side encroaches more on the black, extending higher, while the extremity of the horn is tipped with green, in one specimen distinctly so. There are eight transverse wrinkles to each segment, and the white granulations are more distinct than before. The spiracles are white, with two twin vertical elliptical spots on each side nearly meeting in the middle.

In this stage when disturbed the caterpillar will turn the head, and the front part of the body, represented by the three thoracic segments, over upon the back of the abdominal region so that the feet are held up vertically, as in Datana and other larvae.

Stage V.-Last stage, moulted, 2 I.22 July. Length 54-55 mm. The head is as in the previous stage, but rather more angular on the sides. The lateral yellowish line on the head is very distinct and continued as distinctly on the thoracic segments as far as the middle of the $3^{\text {rd thoracic segment; }}$ beyond this the line is indistinct on the three following segments, becoming distinct again behind the middle of the body.

The prothoracic segment is a little wider than the head, and about one-half as wide as the 3 d thoracic segment.
The lateral yeilowish stripes are distinct, not reaching either the front or hinder end of the segments. The caudal horn is now yellowish; the subdorsal yellowish lines ending on it; it is about one-half as long as the 8th segment is wide when seen from above, and is finely tuberculated with dull amber-colored warts. The upper side of the body is yellowish-green, but the under side is almost exactly of the hue of the under side of the leaf of Ampelopsis, being of a rich soft pea-green and less distinctly and prominently papillated than above. The thoracic legs are yellowish-green.

27 or 28 July it began to contract in length in preparation for pupation, and it assumed the pupa state 30 July.

Duration of stage I, about 7 clays; of stage II, 5 to 6 days; of stage III, 3 to 6 days; of stage IV, 6 to 7 days; of stage $\mathrm{V}$ and last, about 6 days; of the prepupal stage from 2 to 3 days. Total duration of larval life, about 33 days.

\section{Summary of the most important changes.}

I. The glandular bulbous body-hairs disappear after stage $I$.

2. The caudal horn is at the time of hatching slightly longer than the body.

3. Faint traces of the yellowish lateral line appear at the close of stage I, but no oblique stripes.

4. Traces of the oblique yellow stripes appear at the end of stage II.

5. In stage III the body begins to be swollen on the three thoracic and the I st abdominal segments. All the distinc- 
tive lines and markings of the last stage are now indicated. It is also probably the rule among the bombyces, judging by many cases I have observed, that by the $3 \mathrm{~d}$ stage the larva now large and living more conspicuously, assumes the general shape and coloration of the fully fed caterpillar.

\section{The life-history of Ampelophaga myron (Cramer).}

Two of the larval stages have been described by Lintner (Proc. Ent. Soc. Phil. v. 3) the length of his youngest larva being .50 inch; the other stage being the final one. Riley ( $2 \mathrm{~d}$ Missouri Rept. 7I-73) has briefly described the egg, the first and last stages. I am also indebted to $\mathrm{Mr}$. James Angus for the eggs of this sphingid which were sent from New York at the end of June. The larvae were hatched 2 July i 89o, and fed on Ampelopsis leaves.

Egg. - Rounded oval. Length $2 \frac{1}{2}$ $\mathrm{mm}$. The shell, under a Tolles triplet is smooth. It is of the same shape, size and appearance as that of Deidamia inscripta.

Stage I.- Hatched 2 July. Length $5 \mathrm{~mm}$. The larva in this stage, especially at the time of hatching is not only seen to be similar to that of Deidamia inscripta, but is under a high power 'Tolles lens not even distinguishable from it, unless the caundal horn be slightly shorter and less hirsute in the present species. The head is at first larger and broader than the body, and of the same color. Prothoracic segment with a dorsal crescentic shield or flat surface. The caudal horn is long, black and when observed under a high power Tolles triplet, hirsute. The legs are concolorous with the body. Behind the base of the caudal horn both in this and $D$. inscripta, is a deep orange-red discoloration or transverse streak. The body is now wrinkled transversely above. The hairs are glandular, and slightly bulbous at the end.

Three days later, after feeding, and compared with larvae of $D$. inscripta of the same period the body seems to be in $A$. myron a little slenderer, and it also differs in the sutures being slightly yellowish, while the head is of a paler greenish tint. The glandular hairs are of about the same length as those of $D$. inscripta, but perhaps the tubercles are more prominent.

Stage II.-Moulted 9 July. At first the caudal horn is flesh-colored, afterwards turning dark. By I I July it had grown to the length of $10 \mathrm{~mm}$. And now the caterpillar is quite different from that of D. inscripta of the same stage. The body is very slender, the head slightly wider than the body. Each segment has eight wrinkles or folds of the skin which is also spotted with white raised dots. The sutures are yellowish green, contrasting with the body. The caudal horn is pale reddish-chestnut, becoming darker at the extreme tip, which is slightly but distinctly divided at the end, each lobe bearing a bristle. There are as yet no lines or oblique stripes visible.

Stage III? Length I $7 \mathrm{~mm}$. I 8 July, it had probably moulted, but I did not see 
it in the act. The head is as wide as the prothoracic and middle body-segments; the 3 d thoracic and ist abdominal segments are by this time somewhat swollen. A distinct narrow white lateral line is now present, while the dorsal region between the two lines is paler than on the sides of the body. The head is now rough with small pointed tubercles. There are no lateral oblique stripes present. The caudal horn is reddish flesh-colored, becoming darker at the tip.

Stage IV. Length $25 \mathrm{~mm}$. Moulted 24 July. This I suppose to be the third moult. The head is long, somewhat lengthened towards the vertex, and slightly flattened on the sides; the surface is unequally tuberculated with sharp conical white tubercles arranged in irregular longitudinal lines. There is along each side of the head a broad, yellowish lateral stripe, and a faint yellowish shade along each side of the median suture. The yellowish line on the side of the head is continued on the body as a subdorsal whitish line, which is faint on the prothoracic segment; this line behind the middle of the 3 d thoracic is formed of a row of rather large conical tubercles, it again becomes continuously white on the 7 th and 8th abdominal segments, fading out at the base of the caudal horn, which is whitish, with sharp, slender black tubercles on the upper and under side of the horn, the tubercles on the sides being white; the tip of the horn is flesh-colored, and the entire horn is nearly twice as long as the body is thick. The spiracles are raw-sienna brown, with a white spot at each end of the respiratory slit above and below. The thoracic legs are peculiarly spotted with black on the green base, and are reddish cherry at the ends. All the abdominal legs are greenish. The body is thickest on the $3 \mathrm{~d}$ thoracic and Ist abdominal segment. On the $2 \mathrm{~d}$ thoracic to the $5^{\text {th }}$ abdominal segment are faint oblique lateral whitish stripes, bearing white obliquely-arranged white tubercles, those on the first three abdominal segments more distinctly underlined by white. It died 5 Aug., when nearly full-fed.
Note on two species of Datana.From my remarks after the two species of Datana which I described, (Psyche, v. 5, p. 299-300,) it might be inferred that they were compared with a number of allied species. I would like therefore to state that Datana modesta was compared with the type of D. Aloridana in the collection of $\mathrm{Mr}$. Edward L. Graef, and that D. palmii was compared with a type of $D$. integerrima $G$.
$\&$ R., in the collection of the late Coleman T. Robinson, now in the American museum of natural history, N. Y.

William Beutenmaller.

Edwards's Bibliography of TransFORMATIONS.--It will be strange if an impetus is not given to the study of the earlier stages of lepidoptera in this country by the bibliograhy of the literature of the subject, prac- 

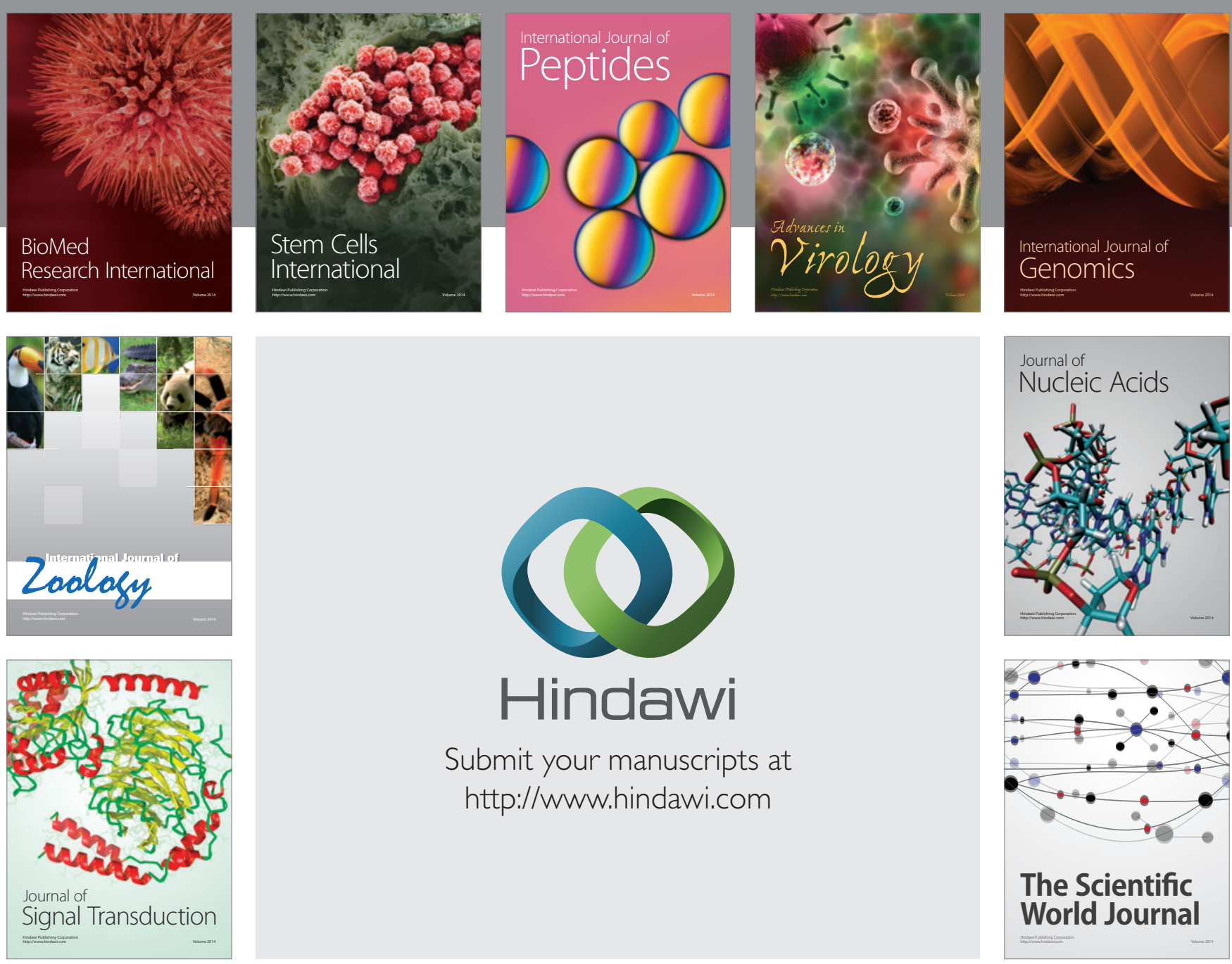

Submit your manuscripts at

http://www.hindawi.com
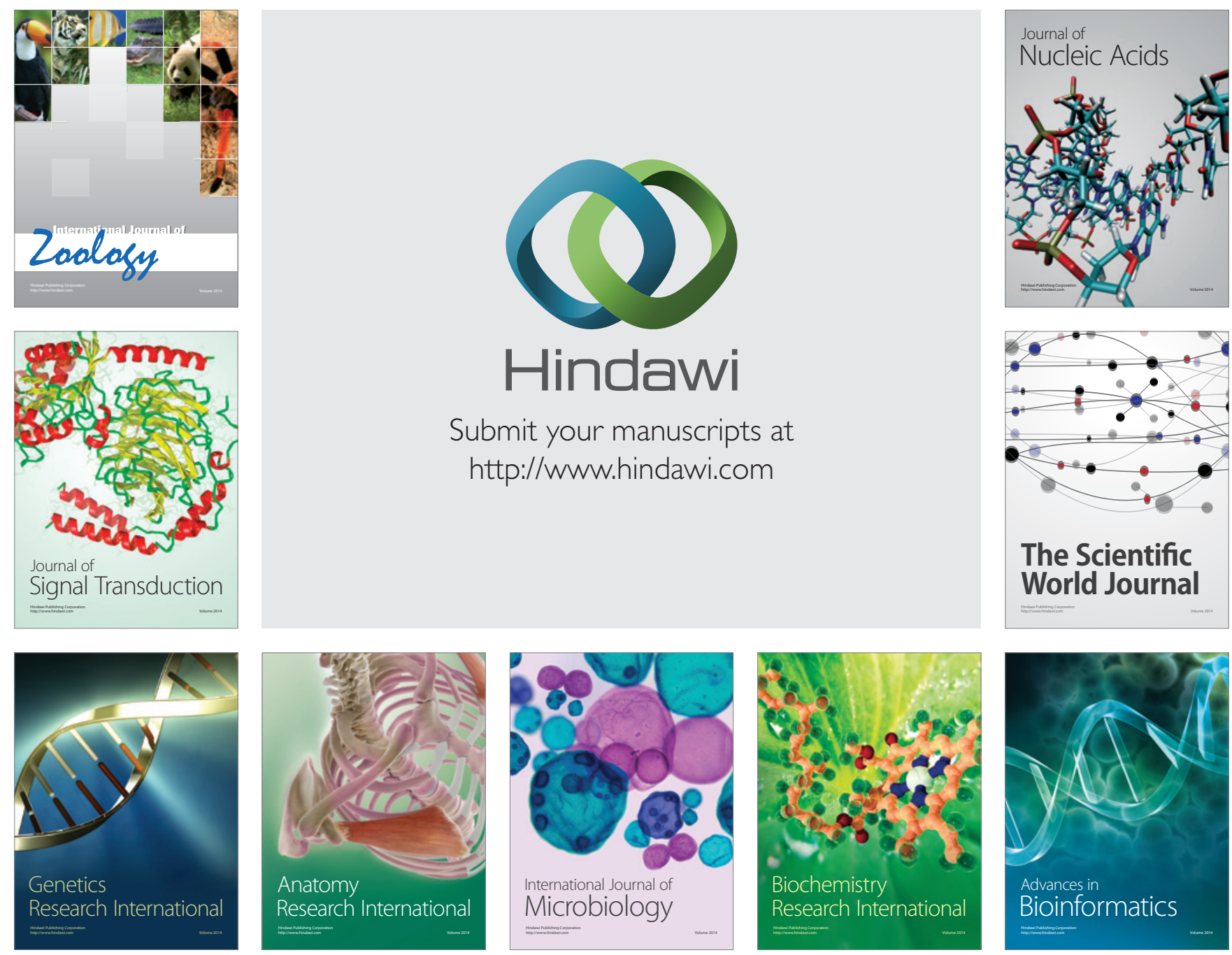

The Scientific World Journal
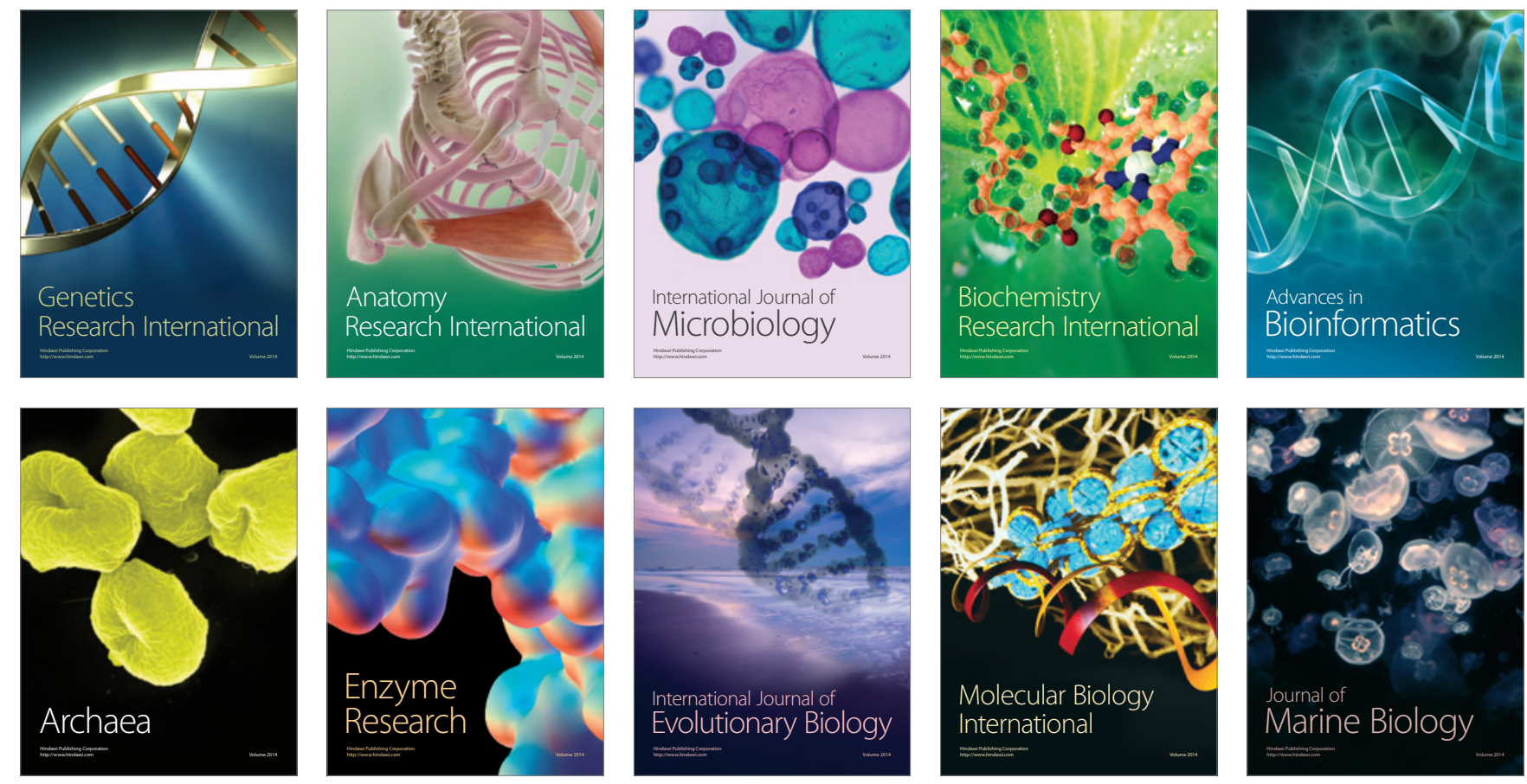